Download

UDC 911.3:30/33(477.8)

https://doi.org/10.17721/2308

$\underline{-135 X .2020 .59 .51-58}$

Smochko Nataliia Mykhailivna,

Candidate of Geographical Sciences, Associate Professor, http://orcid.org/0000-0002-2440-5737 Mukachevo State University, Mukachevo, Ukraine,

e-mail: natazak@ukr.net

\title{
ANALYSIS OF THE CONCEPTUAL-TERMINOLOGICAL SYSTEMS OF SOCIAL GEOGRAPHY AND RELATIONSHIPS BETWEEN THEM
}

The purpose of this research work is to identify and analyse the most important conceptual and terminological systems of social geography and the relationships between them.

Method. General scientific methods, including analysis, scientific synthesis, analytical method, methods of comparison and generalization were used in the study. Accordingly, the need to identify the category of monodevelopment and its inherent differences in the theory of social geography requires a detailed consideration of its etymology, semantic separation from other categories, i.e. scientific justification considering the specifics of geographical understanding. In the course of the research the method of classification had been used in the separation of the 
constituent elements of the territories of monodevelopment.

The scientific novelty lies in the disclosure of the conceptual and terminological apparatus of social geography and its structuring into a number of conceptual and terminological systems, within which the content of concepts is deepened, the terms denoting certain concepts are specified, in particular the concept of «monodevelopment» in socio-geographical science, taking into account, first of all, the attributes of the territory (properties, relations, processes). It has been revealed that monodevelopment is aimed at the formation of territorial social systems of the highest hierarchical level, in the structure of which individual elements will begin their own monodevelopment, which will end with differentiation or integration of subsystems of the territorial social system. The main attributes of the territory in the interpretation of monodevelopment in social geography had been analyzed. Based on the classification of attributes of the territory (properties, relations, processes) formed in the theory of social geography, the author singled out new types of monodevelopment of the territory with increasing weight of one element, such as monoresource, monodemographic, monofunctional, monocentric development and others.

Practical meaning. The results of this study contribute to a deeper socio-geographical understanding of the processes of monodevelopment, their genesis, features of their course and provide an opportunity to model the long-term development of territorial social systems, to achieve expected results due to long-term transformation. They can be used for further study of monosystems of different hierarchical levels, as well as for the development of practical recommendations and programs for the development of individual monoterritories. It is especially important to clarify the category of «monoterritory» and the separation of monoterritories as special territorial formations, which will further determine aspects of the development of this type of territorial formation. It is extremely important in today's decentralization reform in Ukraine, when new united territorial communities are formed; many of which are economically monodirectional.

Key words: conceptual and terminological system, monodevelopment, attributes of territory, monosystem bundles, territorial system of monodevelopment.

References:

1. Alaev Э.B. Sotsyalno-эkonomycheskaia heohrafyia: poniatyino-termynolohycheskyi slovar /

Э.B. Alaev. - M.: Mыsl, 1983. - 350 s. 
2. Bibik N.V. Modeli rehionalnoho rozvytku: teoretychni aspekty y osoblyvosti vykorystannia. URL: http://www.nbuv.gov.ua/portal/soc_gum/Vdnuet/econ/2009_4/2.pdf.

3. Bila S.O. Reformuvannia derzhavnoho upravlinnia rehionalnym rozvytkom : stan, problemy, perspektyvy / S.O. Bila, O.V. Shevchenko, M.O. Kushnir, V.I. Zhuk ta in. -K. : NISD, 2012. - 96 s. URL: https://niss.gov.ua/sites/default/files/2012-06/0621_dop.pdf

4. Varnalii Z.S. Rehiony Ukrainy: problemy ta priorytety sotsialno-ekonomichnoho rozvytku: monohrafiia / za red. Z.S. Varnaliia. - K. : Znannia Ukrainy, 2005. - $498 \mathrm{~s}$.

5. Dolishnii M.I. Henetyko-evoliutsiina paradyhma mekhanizmu rehionalnoi polityky // Rehionalna polityka ta mekhanizmy yii realizatsii / za red. M.I.Dolishnoho. - K.: Nauk. dumka, 2003. - S. 14-17. - (Proekt «Naukova knyha»).

6. Ishchuk I.S. Heohrafiia promyslovykh kompleksiv / I.S.Ishchuk, O.V. Hladkyi - K. Znannia 2011. $-375 \mathrm{~s}$.

7. Lendel M. Spetsialni instytuty rozvytku terytorii: yevropeiskyi dosvid // Instytuty ta instrumenty rozvytku terytorii. Na shliakhu do yevropeiskykh pryntsypiv / Kyiv. tsentr In-tu Skhid - Zakhid; Za red. S. Maksymenka. - K.: Milenium, 2001. - S. 67-148.

8. Maruniak Ye.O. Prostorovi dylemy hlobalizatsii ta yikh kontseptualizatsiia / Ye.O. Maruniak // Ukrainskyi heohrafichnyi zhurnal - 2012, № 4-S. 36-42.

9. Oliinyk V.D. Suspilno-heohrafichni aspekty rehionalnoi dyversyfikatsii v Ukraini. avtoref. k.g.n. spets.11.00.02. ekonomichna ta sotsialna heohrafiia. - Odesa, 2010. - $26 \mathrm{~s}$.

10. Oliinyk Ya.B. Rehionalna ekonomika: Navchalnyi posibnyk / Ya.B. Oliinyk, S.P. Zapototskyi, 
O.lu. Kononenko, ta in. - K. : KNT, Vydavets Fursa S.la., 2007. - 444 s.

11. Oliinyk Ya.B. Stratehiia rozvytku ekonomichnoi i sotsialnoi heohrafii / Ya.B. Oliinyk, A.V. Stepanenko // Chasopys sotsialno-ekonomichnoi heohrafii: Mizhrehionalnyi zb. naukovykh prats - Kh.: KhNU im. V.N. Karazina, 2009. - Vyp. 7. - S.6-15.

12. Palamarchuk M.M. Ekonomichna i sotsialna heohrafiia Ukrainy z osnovamy teorii: Navch. posib. / M.M. Palamarchuk, A.M. Palamarchuk - K.: Znannia, 1998. - 416 s.

13. Pidhrushnyi H.P. Terytorialna orhanizatsiia suspilstva: suchasni pidkhody do rozuminnia katehorii ta yii praktychne znachennia / H.P. Pidhrushnyi // Ukrainskyi heohrafichnyi zhurnal. 2010. - 4. - S.41.

14. Pistun M.D. Osnovy teorii suspilnoi heohrafii / M.D. Pistun - K.: Vyshcha shk., 1996. S.168.

15. Reformuvannia administratyvno-terytorialnoho ustroiu subrehionalnoho rivnia (raioniv). URL: https://decentralization.gov.ua/new-rayons].

16. Tomareva-Patlakhova V.V. Modeli rehionalnoho rozvytku v konteksti ekonomichnykh reform / V.V Tomareva-Patlakhova // Derzhava ta rehiony. - Seriia: Ekonomika ta pidpryiemnytstvo, 2013 r., № 1 (70). - S. 76-80.

17. Topchyev A.H. Prostranstvennaia orhanyzatsyia heohrafycheskykh kompleksov y system. / A.H. Topchyev - Kyev-Odessa: Vusshaia shkola, 1988. - 187 s.

18. Topchiiev O. H. Heohrafiia v umovakh novitnoi naukovoi revoliutsii / O. H. Topchiiev // Heohrafiia. - 2008. - №13/14. - S. 47-49. 
19. Topchiiev O.H. Suspilno-heohrafichni doslidzhennia: metodolohiia, metody, metodyky. / O. H. Topchiiev - Odesa: Astroprynt, 2005. - S.166.

20. Trofymova V.V. Kontseptsiia staloho rozvytku yak osnova postindustrialnykh modelei rozvytku / V.V. Trofymova // Investytsii: praktyka ta dosvid - 2010. - № 8. - S. 33-37

21. Shablii O.I. Cuspilna heohrafiia : teoriia, istoriia, ukrainoznavchi studii / O.I. Shablii. - Lviv: Lv. nats. un-t im.I.Franka, 2001. - S. 25-26.

22. Shablii O.I. Osnovy zahalnoi suspilnoi heohrafii / O.I. Shablii. - Lviv: Vydavnychyi tsentr LNU im. Ivana Franka, 2003. - 444 s.

23. Shablii O.I. Suspilna heohrafiia: u dvokh kn. Knyha persha. Problemy teorii, istorii ta metodyky doslidzhennia / O.I. Shablii. - Lviv : LNU imeni Ivana Franka, 2015. - 814 s.

24. Shevchuk I.B. Informatsiinyi rozvytok rehioniv kriz pryzmu teorii rehionalnoi ekonomiky ta rehionalnoho zrostannia. Scientific and educational journal «THE GENESIS OF GENIUS». 2014, №3. - s. 77-79

25. Shevchuk L.T. Sotsialna heohrafiia: navchalnyi posibnyk. / L.T. Shevchuk - K.: Znannia, 2007. -350 s.

26. Janelle D.G. Time-Space in Geography / D.G. Janelle // International Encyclopedia of the Social \& Behavioral Sciences, 2001 P.157

Надійшла до редколегії 08.11.2020 